\title{
Pengaruh Gaya Belajar Terhadap Hasil Belajar Kognitif Siswa Pada Pokok Bahasan Ikatan Kimia
}

\author{
Christiana Niken Larasati, Romlah Dwi Cahyani, Murtihapsari \\ Universitas Papua \\ murtihapsari.kadarusman@gmail.com
}

Article History

received 30/10/2021

revised 10/11/2021

accepted 24/12/2021

\begin{abstract}
The role of education can prepare students through learning activities in conducting guidance, teaching, and training based on the character and competence of students. Student learning styles are very important to know so that a teacher can understand the characteristics of each individual. This study aims to determine (1) the effect of learning styles on cognitive learning outcomes of class X IPA students of SMA Negeri 1 Manokwari on the subject of Chemical Bonds, (2) the relationship between learning styles and cognitive learning outcomes of class X IPA students of SMA Negeri 1 Manokwari in the main discussion of Chemical Bonds. The subjects of this study were students of class X IPA 1 to X IPA 4 at SMA Negeri 1 Manokwari in the academis year 2019/2020 who were taken by purposive sampling technique. The data analysis of this study used a simple linear regression test and a correlation tests using SPPS 21. The result showed that: (1) there is a significant effect between learning styles on cognitive learning outcomes of class X IPA students in SMA Negeri 1 Manokwari on the subject of chemical bonds based on the level of sig $0,00<0,05$, (2) there is significant relationship between learning styles on cognitive learning outcomes of class X IPA students in SMA Negeri 1 Manokwari on the subject of chemical bonds based on the level of sig 0,00<0,05.
\end{abstract}

Keywords: Learning styles, cognitive learning outcomes, learning activitie, student

\begin{abstract}
Abstrak
Peranan pendidikan dapat menyiapkan siswa melalui kegiatan pembelajaran melalui bimbingan, pengajaran, dan pelatihan berbasis karakter dan kompetensi siswa melalui gaya belajar. Gaya belajar siswa sangat penting diketahui agar seorang pengajar dapat memahami karakteristik tiap individu. Penelitian ini bertujuan untuk mengetahui (1) pengaruh gaya belajar terhadap hasil belajar kognitif siswa kelas X IPA SMA Negeri 1 Manokwari pada mata pelajaran Ikatan Kimia, (2) hubungan antara gaya belajar dengan hasil belajar kognitif siswa kelas X IPA siswa SMA Negeri 1 Manokwari dalam pembahasan utama Ikatan Kimia. Subyek penelitian ini adalah siswa kelas X IPA 1 sampai dengan X IPA 4 SMA Negeri 1 Manokwari tahun pelajaran 2019/2020 yang diambil dengan teknik purposive sampling. Analisis data penelitian ini menggunakan uji regresi linier sederhana dan uji korelasi menggunakan SPPS 21. Hasil penelitian menunjukkan bahwa: (1) terdapat pengaruh yang signifikan antara gaya belajar terhadap hasil belajar kognitif siswa kelas X IPA SMA Negeri 1 Manokwari pada mata pelajaran ikatan kimia berdasarkan taraf sig $0,00<0,05,(2)$ terdapat hubungan yang signifikan antara gaya belajar terhadap hasil belajar kognitif siswa kelas $X$ IPA SMA Negeri 1 Manokwari pada mata pelajaran ikatan kimia berdasarkan tingkat sig $0,00<0,05$.
\end{abstract}

Kata kunci: gaya belajar, hasil belajar kognitif, aktivitas belajar, siswa 


\section{PENDAHULUAN}

Kegiatan untuk meningkatkan pengetahuan umum dalam penguasaan teori, keterampilan, memutuskan dan mencari solusi atas persoalan-persoalan dalam meningkatkan kualitas sumber daya manusia untuk mencapai tujuan ke arah yang lebih baik, dapat diperoleh melalui pendidikan (Azizah et al., 2019) Pendidikan sebagai usaha sadar untuk menyiapkan siswa melalui kegiatan bimbingan, pengajaran, dan pelatihan di masa yang akan dating (Imtima, 2007). Tujuan pendidikan yaitu untuk mengembangkan kemampuan siswa agar menjadi manusia yang beriman dan bertakwa kepada Tuhan Yang Maha Esa, berakhlak mulia, dan menjadi warga negara yang demokratis (Depdiknas, 2003).

Ketercapaian tujuan pendidikan nasional berkembang pesat yang kemudian harus mampu diselaraskan dengan kurikulum sebagai program penunjang sesuai tuntutan zaman (Wahyuni, 2015). Kurikulum merupakan dokumen perencanaan tentang tujuan yang harus dicapai, isi materi dan pengalaman belajar dari siswa, strategi dan cara yang dapat dikembangkan, evaluasi yang dirancang untuk mengumpulkan informasi (Sanjaya, 2010). Pengembangan kurikulum revisi 2013 telah diterapkan secara umum di sekolah namun masih terdapat beberapa sekolah yang menggunakan Kurikulum Tingkat Satuan Pendidikan (KTSP). Penerapan kurikulum 2013 disesuaikan dengan kriteria yang telah ditetapkan oleh pemerintah. Kurikulum 2013 merupakan kurikulum yang berbasis karakter dan kompetensi siswa. Kompetensi siswa untuk mewujudkan potensi diri dan pembentukan karakter dalam proses pembelajaran (Mulyasa, 2013). Salah satu proses pembelajaran yang dilakukan oleh guru dan siswa dengan menerapkan kriteria berbasis karakter diantaranya ilmu kimia.

IImu kimia yang mempelajari materi, sifat dan struktur zat, perubahan zat, reaksi kimia, hukum-hukum dan asas-asas yang menjelaskan tentang perubahan, dan konsepkonsep serta teori-teori yang saling berkaitan dalam kehidupan sehari-hari (Effendy, 2006). Fenomena pembelajaran ilmu kimia saat ini menunjukkan bahwa beberapa siswa merasa kesulitan dalam mempelajari kimia. Tingkat kesulitan dalam memahami kimia yang tinggi disebabkan oleh karakteristrik ilmu kimia, antara lain beberapa konsepnya bersifat abstrak dan berurutan, adanya materi kimia yang berhubungan dengan perhitungan (Winarti, 2001). Kesulitan yang dialami siswa mempengaruhi hasil belajar, dimana akan menyebabkan keberhasilan belajar yang rendah.

Hasil yang rendah ini disebabkan dalam belajar disebabkan oleh banyak faktor, diantaranya adalah : kondisi siswa, penjelasan guru, strategi dan metode pembelajaran, suasana dan lingkungan belajar, kecerdasan siswa, serta gaya belajar (Ghufron \& Suminta, 2012). Selain faktor guru dan siswa, maka faktor gaya belajar pula sangat terlihat nyata terhadap siswa.

Gaya belajar adalah kemampuan untuk menyerap informasi dengan mudah, mengatur dan mengolah informasi tersebut (Deporter, 2005). Penelitian tentang gaya belajar oleh Safrianti, 2017, didapatkan hasil terdapatkan pengaruh yang signifikan antara gaya belajar terhadap hasil belajar siswa sebesar $46,9 \%$ pada gaya belajar visual, $43,6 \%$ pada gaya belajar auditorial, dan gaya belajar kinestetik sebesar $42,3 \%$.

Berdasarkan hasil pengamatan pada penelitian ini maka belum pernah diteliti sebelumnya dan ditemukan beberapa masalah diantaranya kurang optimalnya hasil belajar siswa khususnya pada materi kimia. Jadi tujuan penelitian ini untuk memperoleh data pengaruh gaya belajar terhadap hasil belajar kognitif siswa pada mata pelajaran kimia. Proses pembelajaran, terlihat beberapa siswa yang tidak fokus memperhatikan saat guru menyampaikan pelajaran, ada yang bermalas-malasan, tidak fokus maupun berbicara dengan teman. Siswa juga merasa kesulitan dalam memahami materi kimia khususnya Ikatan Kimia sehingga berdampak terhadap perolehan nilai siswa yang sebagian besar masih di bawah Kriteria Ketuntasan Minimum (KKM) yang sebesar 75. 


\section{METODE}

Penelitian ini dilaksanakan di SMA Negeri 1 Manokwari kelas X IPA. Metode yang digunakan yaitu penelitian kuantitatif dan termasuk dalam penelitian ex-post facto dengan pendekatan deskriptif.

Penelitian ini menggunakan populasi semua siswa kelas X IPA di SMA Negeri 1 Manokwari pada tahun ajaran 2019/2020 yang berjumlah 300 (tiga ratus) siswa. Adapun teknik pengambilan sampel dalam penelitian ini menggunakan teknik purposive sampling atau pengambilan sampel dengan tujuan dan pertimbangan tertentu. Sampel pada penelitian ini yaitu berjumlah 125 (seratus dua puluh lima) siswa dari kelas X IPA 1 - X IPA 4.

Teknik pengumpulan data yang dilakukan dalam peneltian ini yaitu observasi, wawancara, dokumentasi, dan angket. Teknik observasi digunakan untuk menggali data siswa kelas X IPA di SMA Negeri 1 Manokwari. Instrumen yang digunakan berupa angket dengan skala likert. Skala likert merupakan suatu instrumen untuk mengukur persepsi atau sikap seseorang yang diinginkan oleh para peneliti dengan cara mengajukan beberapa pertanyaan tentang fenomena sosial kepada responden (Sukmadinata, 2013).

Variabel yang akan diukur dalam skala likert dijabarkan menjadi indikator varibel, kemudian indikator tersebut dijadikan sebagai titik tolak untuk menyusun item-item instrumen yang berupa pernyataan atau pertanyaan (Sugiyono, 2018). Angket yang disusun dengan skala likert dalam penelitian ini siswa hanya diminta untuk memberi tanda checklist $(\sqrt{ })$ pada pilihan jawaban yang tersedia sesuai dengan keadaan diri siswa. Selain itu digunakan teknik Wawancara tidak terstruktur dimana wawancara yang bebas dimana peneliti tidak menggunakan pedoman wawancara yang telah tersusun secara sistematis dan lengkap untuk mengumpulkan data. Pedoman wawancara yang digunakan hanya berupa garis-garis besar permasalahan yang akan ditanyakan (Sugiyono, 2018).

Teknik analisis data dalam penelitian ini menggunakan uji prasyarat analisis data dan uji hipotesis. Uji prasyarat analisis data meliputi uji normalitas dan uji homogenitas. Uji hipotesis menggunakan uji regresi linear sederhana dan uji korelasi.

\section{HASIL DAN PEMBAHASAN}

Data yang diperoleh dalam penelitian ini berupa data hasil pengisian angket gaya belajar dan data hasil belajar kognitif siswa pada pokok bahasan Ikatan Kimia. Penelitian ini merupakan penelitian kuantitatif deskriptif, sehingga data hasil penelitian yang diperoleh akan didiskripsikan sesuai hasil yang telah dianalisis menggunakan software SPSS 21.

Sebelum data dianalisis maka hasil data yang diperoleh terlebih dahulu dilakukan uji prasyarat analisis dengan menggunakan uji normalitas dan uji homogenitas. Metode yang digunakan untuk uji normalitas pada penelitian ini adalah dengan menggunakan uji Kolmogorov-Smirnov dengan aplikasi SPSS 21. Hasil uji normalitas dapat dilihat pada Tabel 1 dan Tabel 2.

Tabel 1. Data Hasil Uji Normalitas Angket Gaya Belajar

\begin{tabular}{cccccc}
\hline Data & Statistik & Df & Sig & $\alpha$ & Keterangan \\
\hline Gaya Belajar & 0,099 & 125 & 0,103 & 0,05 & Normal \\
\hline
\end{tabular}

Tabel 2. Data Hasil Uji Normalitas Hasil Belajar Kognitif

\begin{tabular}{|c|c|c|c|c|c|}
\hline Data & Statistik & Df & Sig & & Keterangan \\
\hline
\end{tabular}




\begin{tabular}{cccccc}
\hline $\begin{array}{c}\text { Hasil } \\
\text { Belajar } \\
\text { Kognitif }\end{array}$ & 0,202 & 125 & 0,000 & 0,05 & Tidak Normal \\
\hline
\end{tabular}

Uji homogenitas dalam penelitian ini dilakukan untuk mengetahui dan meyakinkan bahwa sampel/kelompok data dalam penelitian ini berasal dari populasi yang memiliki varians sama (homogen). Peneliti menggunakan Leneve Test dalam aplikasi SPSS 21 untuk melakukan uji homogenitas. Hasil uji homogenitas dapat dilihat pada Tabel 3 .

Tabel 3 Hasil Uji Homogenitas

\begin{tabular}{cccccc}
\hline Data & df1 & df2 & Sig. & $\alpha$ & Keterangan \\
\hline $\begin{array}{c}\text { Gaya Belajar } \\
\text { Siswa }\end{array}$ & 11 & 111 & 0,777 & 0,05 & Homogen \\
\hline
\end{tabular}

Menurut penelitian oleh (Larasati \& Damopolii, 2018) menunjukkan kemampuan berpikir kristis mahasiswa kelompok 1 secara auditorial menghasilkan data tidak normal, untuk kelompok 2 secara kinestetik menghasilkan data normal, selanjutnya kelompok 3 secara visual menghasilkan data normal. Kemudian akan dilanjutkan uji non parametrik karena ditemukan salah satu data tidak memenuhi normalitas.

Penyajian Data Angket Gaya Belajar Siswa

Tipe gaya belajar yang dominan pada siswa dapat diketahui dari hasil perhitungan pilihan jawaban angket. Setelah diketahui masing-masing hasil pengisian angket, maka maka dapat dikategorikan berdasarkan kecenderungan gaya belajar siswa pada Tabel 4 .

\section{Tabel 4 Klasifikasi Gaya Belajar Siswa}

\begin{tabular}{ccc}
\hline No & Gaya Belajar & Jumlah Siswa \\
\hline 1 & Visual & 48 \\
2 & Auditori & 8 \\
3 & Kinestetik & 69 \\
\hline & Jumlah & 125 \\
\hline
\end{tabular}

Berdasarkan Tabel 4 di atas, maka dihitung persentasi dari masing-masing gaya belajar dengan cara membandingkan jumlah siswa dengan jumlah keseluruhan siswa yang menjadi sampel dalam penelitian ini. Berikut disajikan tabel distribusi frekuensi siswa berdasarkan kecenderungan gaya belajar beserta besar persentasi pada Tabel 5.

Tabel 5 Distribusi Frekuensi Gaya Kecenderungan Gaya Belajar Siswa

\begin{tabular}{cccc}
\hline No & Gaya Belajar & Jumlah Siswa & Persentasi \\
\hline 1 & Visual & 48 & $38 \%$ \\
2 & Auditori & 8 & $7 \%$ \\
3 & Kinestetik & 69 & $55 \%$ \\
\hline & Jumlah & 125 & $100 \%$ \\
\hline
\end{tabular}


Analisis Hipotesis I

Hipotesis I yang akan diuji dalam penelitian ini adalah pengaruh gaya belajar terhadap hasil belajar kognitif siswa kelas X IPA SMA Negeri 1 Manokwari pada pokok bahasan ikatan kimia. Uji hipotetis I menggunakan uji regresi linear sederhana menggunakan software SPSS 21 dengan kriteria pengujian

yaitu jika nilai sig. $<0,05$ maka gaya belajar berpengaruh signifikan terhadap hasil belajar kognitif dan jika nilai sig. > 0,05 maka gaya belajar tidak berpengaruh signifikan terhadap hasil belajar kognitif. Hasil uji regresi linear sederhana dapat dilihat pada Tabel 6 dan Gambar 1.

Tabel 6 Hasil Uji Regresi Linear Sederhana

\begin{tabular}{|c|c|c|c|c|c|}
\hline \multicolumn{2}{|c|}{ Data } & \multirow[b]{2}{*}{ Sig } & \multirow[b]{2}{*}{ A } & \multirow{2}{*}{$\begin{array}{c}\mathrm{R} \\
\text { Square }\end{array}$} & \multirow[b]{2}{*}{ Keterangan } \\
\hline $\begin{array}{c}\text { Variabel } \\
\text { bebas }\end{array}$ & Variabel Terikat & & & & \\
\hline Gaya Belajar & $\begin{array}{l}\text { Hasil Belajar } \\
\text { Kognitif }\end{array}$ & 0,00 & 0,05 & 0,12 & $\begin{array}{l}\text { Terdapat } \\
\text { Pengaruh }\end{array}$ \\
\hline
\end{tabular}

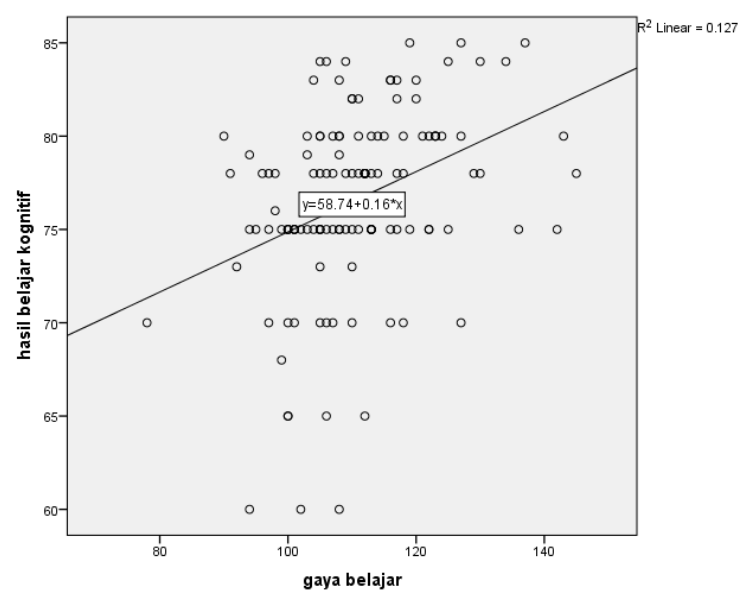

\section{Gambar 1. Grafik Hasil Uji Regresi}

Hipotesis pertama, didapatkan nilai signifikansi gaya belajar dan hasil belajar kognitif siswa $0,000<0,05$ maka $\mathrm{H}_{1}$ diterima dan $\mathrm{H}_{\mathrm{o}}$ ditolak yang berarti bahwa ada pengaruh gaya belajar terhadap hasil belajar kognitif siswa kelas X IPA SMA Negeri 1 Manokwari pada pokok bahasan ikatan kimia. Hal ini pula sesuai dengan penelitian dari (Irawati et al., 2021), yang menyatakan, bahwa adanya pengaruh gaya belajar dan memberikan kontribusi hasil belajar pada mata pelajaran IPA sebesar $21,2 \%$. 


\section{Analisis Hipotesis II}

Hipotesis II yang akan diuji dalam penelitian ini adalah hubungan gaya belajar terhadap hasil belajar kognitif siswa kelas X IPA SMA Negeri 1 Manokwari pada pokok bahasan ikatan kimia. Uji hipotesis II ini menggunakan korelasi Product Moment dengan

bantuan program SPSS 21 dengan kriteria pengujian yaitu jika nilai signifikan < 0,05 maka $\mathrm{H}_{\mathrm{a}}$ diterima. Berikut ini Tabel 7 merupakan hasil uji korelasi sederhana antara variabel gaya belajar dengan hasil belajar kognitif siswa.

Tabel 7 Hasil Uji Korelasi Gaya Belajar

\begin{tabular}{lcccccc}
\hline \multicolumn{2}{c}{ Data } & Sig & A & $\begin{array}{c}\text { Person } \\
\text { Korelasi }\end{array}$ & Keterangan \\
\cline { 1 - 4 } Variabel bebas & Variabel Terikat & Sig & & & & \\
\hline Gaya Belajar & $\begin{array}{c}\text { Hasil Belajar } \\
\text { Kognitif }\end{array}$ & 0,00 & 0,05 & 0,35 & Rendah \\
\hline
\end{tabular}

Hipotesis kedua, didapatkan nilai signifikansi sebesar 0,000 $<0,05$ maka $\mathrm{H}_{1}$ diterima dan $\mathrm{H}_{\mathrm{o}}$ ditolak yang berarti ada hubungan gaya belajar terhadap hasil belajar kognitif siswa.kelas X IPA SMA Negeri 1 Manokwari dan hubungan gaya belajar berkorelasi rendah terhadap hasil belajar kognitif siswa. Oleh karena itu, hal ini sesuai penelitian yang dilaksanakan oleh (Elytasari et al., 2015), menyatakan gaya belajar dan prestasi belajar kimia siswa SMA mendapatkan hasil masing-masing sebesar 29,03\%, 51,61\% 19,36\% dengan memiliki gaya belajar visual, auditori dan lainnya (gaya belajar campuran yaitu gaya visualauditori) dan didapatkan prestasi belajar dengan nilai rata-rata siswa yakni sebesar 85,69 yang termasuk ke dalam katagori sangat baik.

\section{SIMPULAN}

Berdasarkan hasil penelitian, analisis data, dan pembahasan maka dapat disimpulkan bahwa adanya pengaruh yang signifikan antara gaya belajar terhadap hasil belajar kognitif siswa terdapat taraf signifikan 0,00<0,05. Kemudian adanya hubungan yang signifikan antara gaya belajar terhadap hasil belajar kognitif siswa terdapat taraf signifikansi $0,00<0,05$

\section{DAFTAR PUSTAKA}

Azizah, Z. Z. N., Supriyanto, A., \& Agus, T. (2019). Pendidikan Dan Pelatihan Sebagai Upaya Peningkatan Kinerja Pegawai Perpustakaan. Jurnal Dinamika Manajemen Pendidikan, 3(2), 96-100. https://doi.org/10.26740/jdmp.v3n2.p96-100

Depdiknas. (2003). Undang-undang Republik Indonesia nomor 20 Tahun 2003 Tentang Sistem Pendidikan Nasional. In Biro hukum dan organisasi Depdiknas. Biro hukum dan organisasi Depdiknas. https://doi.org/10.30870/educhemia.v5i2.7987 
Deporter, B. (2005). Quantum Learning \& Character development: E-book. Kaifa PT Mizan Pustaka.

Effendy. (2006). A-Level Chemistry for Senior High School Students Volume 1A. Bayumedia.

Elytasari, M., Hidayat, I., \& Ibrahim, A. R. (2015). Gaya Belajar Dan Prestasi Belajar Kimia Siswa SMA. Jurnal Penelitian Pendidikan Kimia: Kajian Hasil Penelitian Pendidikan Kimia, 2(1), 44-50.

Ghufron, M. N., \& Suminta, R. R. (2012). Gaya belajar: Kajian teoritik. Pustaka Pelajar.

Imtima. (2007). IImu dan aplikasi pendidikan. Armico.

Irawati, I., Ilhamdi, M. L., \& Nasruddin, N. (2021). Pengaruh Gaya Belajar Terhadap Hasil Belajar IPA. Jurnal Pijar Mipa, 16(1), 44. https://doi.org/10.29303/jpm.v16i1.2202

Larasati, C. N., \& Damopolii, I. (2018). Pengaruh Gaya Belajar Terhadap Kemampuan Berpikir Kritis Mahasiswa Program Studi Pendidikan Kimia UNIPA Manokwari. Arfak Chem: Chemistry Education Journal, 1(1), 1-4.

Mulyasa. (2013). Pengembangan dan Implementasi Pemikiran Kurikulum. Rosdakarya.

Safrianti, S. D. (2017). Pengaruh gaya belajar visual, auditorial, dan kinestetik terhadap hasil belajar Siswa Kelas X IPS Program Unggulan di MAN 1 Kota Malang. Universitas Islam Negeri Maulana Malik Ibrahim.

Sanjaya, W. (2010). Strategi Pembelajaran Berorientasi Standar Proses pendidikan. Prenada Media Group.

Sugiyono. Metode Penelitian Kuantitatit Kualitatif dan R\&D. Bandung: Alfabeta. 2018.

Suad. (1997). Manajemen Personalia. BPFE.

Sukmadinata, S. Nana. (2005). Metode Penelitian Pendidikan. Bandung: Remaja Rosdakarya.

Wahyuni, F. (2015). Kurikulum Dari Masa Ke Masa. Fakultas Tarbiyah INSURI Ponorogo, 278(1-2), 249-253. https://doi.org/10.1023/A:1013199923212

Winarti, A. (2001). Pembelajaran ilmu kimia dan kontribusinya terhadap perkembangan intelektual. Jurnal Vidya Karya, 19(2), 109-115. 
